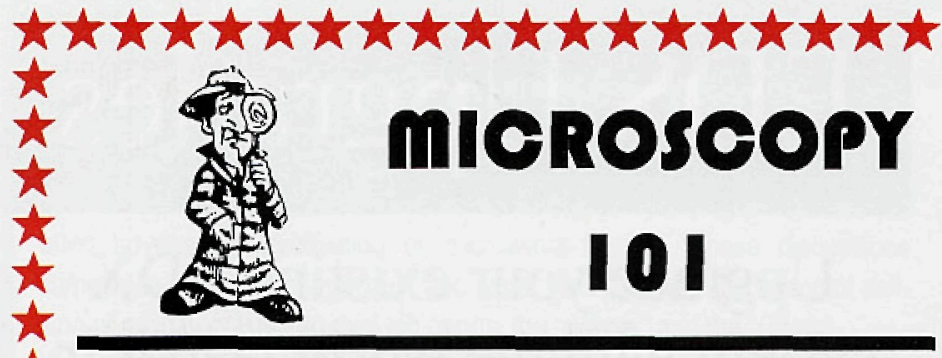

We appreciate the response to this publication feature - and welcome all contributions, Contributions may be sent to Phil Oshel, our Technical Editor at:

औ

负

Mr. Phil Oshel"

(608)833-2885

PO Box 620068

eMail: oshel@terracom.net

Middleton W/ 53562

(608) $833-2885$

PLease note NEW address

\section{Protocol for Preparation of Compact Disks for SEM Analysis}

This simple method uses differences in the coefficient of thermal expansion for separation of materials of differing densities. CDs are made up of a metallic core (usually aluminum or gold) surrounded by a plastic layer on either side. Other methods include dissolving the plastic with various solvents, or by removing the metal layer by etching techniques. Both may work fine, I have tied neither. This protocol uses liquid nitrogen to cool the sample (CD) to a point where the materials separate, and has proved successful with both gold and aluminum CDs.

1) Using tongs, immerse the $C D$ in the liquid nitrogen, after 15 to 30 seconds the CD will sound as if it is cracking. After 30 to 60 seconds, remove the $C D$ from the liquid nitrogen.

2) Place the frozen $C D$ on a firm surface and strike it with a hammer t. (wear safety glasses). The CD will shatter. Alternatively you may wish to $\uparrow$ slap the frozen $C D$ down against the bench top (results of the two techniques are similar), shearing between the plastic and metal interface. The t metal will easily pull away from the surface of the plastic if still in contact.

大 3) Mount the metallic layer, which contains the information tracks ("pits" $\uparrow$ and "lands") on an aluminum stub using double stick conductive carbon tape or tabs. Sputter coating is usually not necessary. Examination with the SEM is fairly routine at this point ( 5 to $15 \mathrm{kV}$ ).

Mike Rock, University of Denver

\section{Surface Replication}

Here's a good trick. I recently wanted to do leaf surface impressions for stomatal counts and was experimenting with cellulose acetate, etc. A physiologist friend, Todd Dawson, comes along and says "have you tried ignition sealer?" Turns out this works really well, and probably would work for any surface

I sprayed the leaf surface with Krylon (of Columbus Ohio. 43215) ignition sealant (used as a spray waterproofing treatment for electrical wires and engine components), let it set for 5 minutes, then peeled off the surface coating with clear tape.

The replica/tape was then simply stuck to a glass slide and examined by phase contrast.

This works well for epidermal cell shape, stomatal shape and distribution, and vein shape. I don't know how well it will work on trichomes and it probably depends on how elaborated they are. A word of caution; it seems that not all ignition sealer sprays are created equal. "Wire Dryer" brand did not work at all. Other companies that manufacture this stuff include Hydrosol, Kleenflo and Spray-pak.

C. John Runions, Cornell University

\section{A Stain For Spirochete Bacteria}

Here Is a method that doesn't require uranyl nitrate, and it is calibrated for a $700 \mathrm{~W}$ microwave.

Chemicals:

$5 \%$ Gelatin

$0.15 \%$ Hydroquinone

$0.5 \%$ Silver Nitrate

$2 \%$ Silver Nitrate

Developer:

Caution: carcinogenic and toxic!

Combine in the order given and prepare just before use:

$2 \%$ Silver Nitrate $\quad 9 \mathrm{~mL}$

$5 \%$ Gelatin $\quad 22.5 \mathrm{~mL}$

$0.15 \%$ Hydroquinone $12 \mathrm{~mL}$

Procedure (Time required: 4-7 minutes):

1) Deparaffinize slides to distilled water.

2) Prepare the developer.

3) Microwave slides in $0.5 \%$ silver nitrate in a plastic Coplin jar for 2 minutes on power level 1 (10\% power, or about 70 Watts) with cap loosely applied. Allow slides to remain in warm solution for 1 minute. NOTE: Fill Coplin jar with $0.5 \%$ silver nitrate to the top of the slide slot. Do not go beyond because it will discolor the slide label.

4) Remove Coplin jar with slides from the microwave and discard the solution.

5) Pour the developer into the Coplin jar with slides.

6) Microwave the slides in the developer for 1 minute on power level one.

7) Remove the slides from the microwave and allow them to remain in the warm solution for 30 to 90 seconds, periodically checking that the sections turn yellow to grayish brown.

8) Wash the slides quickly and thoroughly in hot tap water.

9) Rinse slides in distilled water.

10) Dehydrate slides through 2 changes each of $95 \%$ alcohol and $100 \%$ alcohol.

11) Clear and mount.

Results:

Spirochetes black

Background pale yellow to light brown

References:

Briges, C.H. and L.G. Luna. 1957. Kerr's Improved Warthin-Starry Technique: A Study of Permissible Variations. Lab. Invest. 6:357-367. Baltimore, The Williams \& Wilkins Co.

Carson, F. 1990. Histotechnology: A Self-Instructional Text. pg 203204. ASCP Press, Chicago, IL.

Davis, M.M. 1994. Cleveland Clinic Foundation Histology Special Stains Procedure Manual. Cleveland Clinic, pub. Cleveland, $\mathrm{OH}$.

Green, R.M. 1995. Grant/Riverside Methodist Hospitals Histology Special Stains Procedure Manual Grant/Riverside Methodist Hospitals pub. Columbus, $\mathrm{OH}$ [Ph (614) 566-9177]

Kerr, D.A. 1938. Improved Warthin-Starry Method of Staining Spirochetes in Tissue Sections. Am. J. Clin. Path. 8:63-67.

Luna, L.G. (ed) 1968. Manual of Histologic Staining Methods of the Armed Forces Institute of Pathology. 3rd edition. Pg. 238-240. New York, McGraw-Hill Book Co.

Sheehan, D.C., and B.B. Hrapchak. 1980. Theory and Practice of Histotechnology. 2nd edition. pg 240. Battelle Press, Columbus, $\mathrm{OH}$.

Rod Green, Grant/Riverside Methodist Hospitals, Columbus, Ohio 